\title{
JOHN KNOWLES: LA IMPOSIBILIDAD DE LA INOCENCIA EN A SEPARATE PEACE
}

\author{
DANIEL PASTOR GARCÍA \\ Universidad de Salamanca
}

\begin{abstract}
With the help of a classical motif in American literature, Knowles has written in A Separate Peace a powerful story about humannature whose main characters are some youths moving into the adult world. Innocence and a natural existence are incompatible withsociety that rewards those who are best adapted to its demands.

\section{RESUMEN}

Sirviéndose de un motivo clásico en la literatura norteamericana, el de la inocencia corrompida por las necesidades de la civilización, Knowles crea en $A$ Separate Peace una poderosa historia sobre la naturaleza humana protagonizada por unos adolescentes que están a punto de pasar al mundo de los adultos. La imposibilidad de la inocencia y con ella una existencia ideal resultan incompatibles con las demandas sociales y con una concepción de la vida como un conflicto en el que prevalece el mejor resultado.
\end{abstract}

La publicación de $A$ Separate Peace en 1960 convirtió a John Knowles en uno de los autores más destacados del panorama literario contemporáneo. Nada hacía prever que esta primera novela de un autor desconocido hasta entonces no sólo ganara prestigiosos premios literarios sino que acaparara inesperadamente la atención del público. Si las primeras reseñas fueron rotundas en sus calificaciones, la crítica especializada posterior reconoció con entusiasmo el tratamiento que hace de un tema recurrente en la literatura norteamericana, el de la inocencia corrompida por las necesidades de la civilización, y estudió en profundidad su simbolismo, su peculiar estructura narrativa y su componente autobiográfico. Lo más significativo es no sólo la ininterrumpida popularidad que ha gozado desde su aparición o que haya pasado a formar parte del programa de lecturas de numerosas universidades norteamericanas, sino el hecho de que ha adquirido la categoría de un clásico menor, como hace notar Harold Bloom (Bloom, 2000: 1), un legado literario con el que generaciones enteras de lectores se han identificado plenamente porque descubren que bajo su aparente sencillez se oculta una poderosa reflexión sobre la naturaleza humana. 
En distintas ocasiones Knowles ha explicado que aunque está elaborada a partir de sus propias experiencias como estudiante en un exclusivo internado en Nueva Inglaterra desde 1942 a 1944, su propósito fue dar respuesta al difícil proceso de cambio y sobre todo al clima de incertidumbre, ansiedad y confusión que todos los de su generación sintieron a la edad de diecisiete años ante la inminente perspectiva de participar en la contienda mundial, y lo que empezó como una simple historia de amistad entre muchachos acabó siendo “...one long abject confession, a mea culpa, a tale of crime - if a crime has been committedand of no punishment. It is a story of growth through tragedy..."1, una historia plagada de tensiones, rivalidades y miedos en la que abiertamente se cuestiona las causas de la guerra $\mathrm{y}$, en fin, se descubre la imposibilidad de la inocencia frente a las demandas sociales. Al igual que tantas otras obras contemporáneas, $A$ Separate Peace forma parte de una vasta corriente en las letras norteamericanas en la que dominan los personajes puros, no contaminados, que en vano luchan por preservar su integridad natural y acaban por sucumbir ante una aplastante realidad que no llegan a entender del todo. Knowles cree que las relaciones humanas fracasan no sólo por los imperativos de la sociedad deshumanizada, altamente competitiva, que nos toca vivir sino también porque entran en juego fuerzas y sentimientos antagónicos que suponen una amenaza oculta de la que no somos conscientes. Como apunta en Double Vision, un libro de viajes donde reflexiona sobre las diferencias culturales de distintos países, "American life has an orderly, rather dull and sober surface, but with something berserk stirring in its depths"2. No existe, pues, la inocencia desde el momento mismo en que la condición de la vida es la de un permanente conflicto.

En cierto sentido, A Separate Peace puede leerse casi exclusivamente como una novela de guerra; de hecho el título proviene de A Farewell to Arms en donde Frederic Henry declara su propia paz privada frente a la violencia desencadenada durante la Primera Guerra Mundial. La novela de Knowles, sin embargo, no trata del conflicto entre naciones, ni siquiera habla de grandes batallas, sino que el énfasis recae en el impacto psicológico que la Segunda Guerra Mundial ejerce en las vidas, las actitudes y las emociones de Gene Forrester y Phineas, su mejor amigo, junto a otros adolescentes más, que están muy próximos a ser llamados a filas. La Segunda Guerra Mundial, la expresión máxima de la capacidad de destrucción humana, es la metáfora dominante que se reproduce en otras guerras menores dentro del apacible marco de Devon School. Gene, el narrador de la novela, intenta comprender el mundo y, sobre todo, conocerse a sí mismo, pero la transición de la adolescencia a la condición de adulto, de la inocencia a la experiencia, se vuelve mucho más traumática en un momento de su vida en que todo se está transformando vertiginosamente. Las verdaderas batallas se libran, en efecto, en el interior de su personalidad: Gene se debate entre aceptar la seguridad idílica que proporciona la escuela, o adentrarse en la confusión del mundo de los adultos; al mismo tiempo lucha contra la irrefrenable influencia de Phineas, su visión de la vida y su inmutable mensaje de paz. El resultado de este tortuoso viaje al corazón humano implicará necesariamente el sacrificio de Phineas visto como la verdadera encarnación de una existencia ideal. A Separate Peace es, pues, una hermosa alegoría sobre la pérdida de la inocencia primigenia del hombre y su

\footnotetext{
${ }^{1}$ Knowles, J. 1985. "My Separate Peace” Esquire March: 109.

2 Ibidem, Double Vision: American Thoughts Abroad, 1964.New York: Macmillan, p. 43.
} 
capacidad de destruir los instintos adámicos por lograr su integración en el conjunto social y su incondicional aceptación.

El núcleo central del libro lo constituye, sin duda, lo que Gene identifica vagamente como "...something that might be called double vision..."”, que explica, por un lado, la idea de que la guerra se muestra en un principio como algo alejado de su vida y al final acaba por descubrirse como el resultado de los defectos de la naturaleza humana, y, por otro, la compleja relación de amor-odio que tiene con su amigo ${ }^{4}$. Phineas y Gene, dos personalidades dispares pero afines, encarnan respectivamente dos concepciones incompatibles ante la vida: el eterno conflicto entre el hombre natural, espontáneo, no sujeto a normas, y el hombre civilizado atento siempre a las demandas y convenciones sociales. Esa "double vision", que cobra forma a través de la oposición simbólica entre el mundo ideal y el de la realidad, pasado y presente, verano e invierno, paz y guerra y los dos ríos que cruzan la escuela, recorre la totalidad de la novela Así, podemos ver que Devon School, un auténtico enclave de exquisita elegancia, espíritu deportivo y destacada reputación académica, tiene una sobria apariencia externa que para nada da idea de la magnificencia del interior de sus edificios ni mucho menos de las siniestras operaciones que se llevan a cabo en "The Cage". De la misma manera, mientras que Phineas "the essence of ...peace" (17), es capaz de expresar noblemente su amistad y se muestra como "...a poor deceiver, having had no practice" (104), Gene, al menos hasta que logre una reconciliación consigo mismo, está motivado exclusivamente por un sentimiento ambiguo que define como "...some ignorance inside me, some crazy thing...something blind" (183) que le lleva a vivir atrapado en el miedo y el egoísmo y a creer que "everyone at Devon had many public faces..." (80). El mismo llega a confesar en unos de sus escasos momentos de sinceridad: "...I was used to finding something deadly in things that attracted me; there was always something deadly lurking in anything I wanted, anything I lived. And if it wasn't there, as for example with Phineas, then I put it there myself' (92).

Las apariencias son el recurso defensivo que adopta frente a un mundo que considera hostil. Aunque es considerado como el mejor estudiante de Devon School, no tiene un verdadero interés por los estudios, simplemente aspira a ser el primero de clase para lograr el respeto de todos, y por la misma razón se inventa unos fabulosos orígenes familiares de prestigio. Gene es un perfecto simulador que manipula sutilmente una relación de amistad para su propia conveniencia.

La presencia de la Segunda Guerra Mundial es para el pequeño grupo de adolescentes una amenaza para la mítica paz que se esfuerzan por recrear durante el verano de 1942 . Se trata de la última experiencia de vida en libertad que pueden disfrutar a su manera antes de alcanzar la edad suficiente para entrar en el ejército. Y es precisamente el mundo de la guerra, el mundo de la realidad, lo que Gene quiere evitar a toda costa por mediación de Phineas. Bajo su influencia, Devon School se convierte en una especie de paraíso no

\footnotetext{
${ }^{3}$ ibidem, A Separate Peace, New York: Bantam Books, 1975, p. 177. En adelante las citas de esta novela, que tendrán su página correspondiente entre paréntesis, se refieren a esta edición.

${ }^{4} \mathrm{Su}$ ambigua relación ha sido motivo de inspiración para los críticos, y mientras unos ven en ella el clásico desarrollo del tema del Doble o Doppelgänger (Rosenfield, 1963: 326-344; Foster, 1968: 34-40; Slethaug, 1984:45-56), otros prefieren destacar que ambos personajes representan los lados contrarios en la naturaleza humana (Bryant, 1990) y unos pocos ven implicaciones homosexuales (Sarrotte, 1978:4545-46).
} 
corrompido, el refugio perfecto, donde pueden vivir entregados a los juegos y cometiendo inocentes actos de indisciplina. Todo parece favorecer esa sensación de irrealidad del conflicto bélico: las costumbres del internado se relajan e incluso los profesores se vuelven más permisivos. El mismo entorno natural contribuye a crear esa imagen inmutable del jardín bíblico trasladado a Devon School, como si fuera el último reducto de la inocencia donde sus personalidades pueden encontrar verdadera expresión:

The dormitories... were massive and almost anonymous behind their thick layers of ivy, big, old-looking leaves you would have thought stayed there winter and summer, permanent hanging gardens in New Hampshire...the trees...too seemed permanent and never changing, an untouched, unreachable world high in space.... Beyond the gym and the fields began the woods... which in my imagination were the beginning of the great northern forests. I thought that... trees reached in an unbroken, widening corridor so far to the north that no one had ever seen the other end.... We seemed to be playing on the tame fringe of the last and greatest wilderness... (22-23)

Sólo Phineas es el único que sabe dirigir sus actividades y transmitir verdaderos sentimientos de amor y generosidad. Sus extraordinarias facultades físicas, su arrolladora personalidad y su naturaleza perfecta le convierten en el joven ideal que todos admiran y respetan. Es el mejor deportista de la escuela, aunque, como observa Gene, no busca el reconocimiento público ni ningún tipo de honores, y sobre todo es una persona imaginativa que crea sin cesar improvisados juegos y diversiones (como saltar desde las ramas de un enorme árbol a las aguas del río Devon, el "blitzball", o reunirse por las noches como parte de una sociedad secreta), que son la expresión misma de su energía desbordante y de su talante: no hay reglas fijas predeterminadas, o cuando las hay pueden ser improvisadas en el momento por otras nuevas, siempre, en fin, que se consiga que todos los participantes disfruten la experiencia del juego y se rompa la rutina escolar. Phineas concibe el mundo como una unidad indivisible donde todo se interrelaciona armónicamente. La vida es una hermosa experiencia digna de ser disfrutada con entusiasmo, como si cada instante fuera siempre un motivo de exaltación indiscriminada hacia todo que, en correspondencia, genera indisolubles vínculos de afecto, “...when you really love something then it loves you back, in whatever way it has to love" (103). En su sistema de valores no hay cabida para el mal ni para la guerra; ésta forma parte de ese estado generalizado de corrupción que identifica con los adultos, siempre vistos como seres arrogantes, superficiales, carentes de energía, empeñados en mantener una actitud destructiva ante la vida por su afán de imponerse a todo por la fuerza. ${ }^{5}$ Para él, en cambio, las relaciones humanas sólo se definen por los juegos y nada ni nadie puede regular las acciones espontáneas de cada uno, “...authority (was) the necessary evil against which happiness was achieved by reaction” (11).

Gene se convierte en su mejor amigo pero no puede soportar su bondad natural. El intenta ser un adulto y comportarse de acuerdo con sus expectativas pero teme desafiar las

\footnotetext{
${ }^{5}$ Como ha observado Ely (Karson, 1999: 33-35) incluso sus mismos apellidos suenan ridículos: Mr PatchWithers, Reverend Carhart, Miss Windbag, etc. Todos ellos se caracterizan por sus observaciones pomposas o estúpidas, o son descritos como "fat", "gassy", "fragile", "inane", etc.
} 
reglas en el convencimiento de que "If you broke the rules, then they broke you" (66), aunque al mismo tiempo no quiere perder la consideración que le tienen los demás muchachos. Tiene un arraigado espíritu competitivo que le hace ver la vida exclusivamente como un conflicto permanente, "the war was and is reality for me" (132) donde sólo existen vencedores o vencidos. Y él por supuesto quiere ser un triunfador. Durante buena parte del verano sigue a Phineas en todas sus propuestas y diversiones, pero en ningún momento hace el esfuerzo por compartir sus juegos sin calibrar con calculada exactitud las consecuencias que le pueden acarrear. Puede mostrarse orgulloso ante los demás de ser su inseparable compañero e incluso admirar sus proezas, pero odia su actitud relajada y natural que hace que sea siempre el centro de atención de todos. Gene es metódico y busca sobre todo consistencia lógica y regularidad en sus hábitos, y mientras Phineas es casi un ser excepcional de envidiable equilibrio interior, él, por el contrario, se reconoce como una persona fragmentada, débil, acosado por múltiples complejos e inhibicione. Desea las mismas cualidades de Phineas que él carece, una respuesta espontánea e imaginativa ante la vida, pero piensa que su influencia es excesiva y a él le toca siempre el papel de subordinado, de aliado pasivo sin iniciativa propia. Son las continuas transgresiones como desafiar las normas escolares, saltar a diario del enorme árbol, perder clases o comidas, escaparse a la playa, en suma, "acting against every instinct of my nature" (26), las que le hacen creer que trata de destruir su reputación de buen estudiante. Empieza a ver a Phineas como su rival y concluye que su relación ha sido regulada exclusivamente por la envidia. Es entonces su enemigo irreconciliable al que desea eliminar provocándole una caída inesperada desde el árbol:

I found it. I found a single sustaining thought... You and Phineas are even already. You are even in enmity. You are both coldly driving ahead for yourselves alone... Finny had deliberately set out to wreck my studies... that explained that I share all his diversions... That way he, the great athlete, would be ahead of me. It was all cold trickery, it was all calculated, it was all enmity... I felt better... The deadly rivalry was on both sides after all...

... it was what you had in your heart that counted. And I had detected that Finny's was a den of lonely, selfish ambition. He was no better than I was, no matter who won all the contests. $(45,48)$

Más que ningún otro episodio, el incidente del árbol divide la novela en dos mitades contrapuestas. Representa, por un lado, la pérdida de influencia de Phineas y, por otro, el comienzo de la pérdida de la inocencia de Gene y su paulatina aceptación del mundo exterior. Phineas sale físicamente dañado tras la caída y hasta su muerte irá gradualmente perdiendo parte de su energía; en adelante no sólo será para siempre un lisiado sino que pasará a ser un vago referente simbólico de una inocencia imposible. Gene, por el contrario, sale fortalecido de la caída, ganará más seguridad en sí mismo, aprenderá a conocer la existencia del mal y también a conocerse a sí mismo. El paso de un estadio de su vida a otro corre paralelo al suceder de las estaciones, a la oposición de los dos ríos que fluyen en los campos de Devon School, y a la opresiva presencia del ambiente bélico en la escuela. 
Si el verano ha supuesto un breve intervalo de paz y el río Devon está asimilado para él a la "atmosphere of reverie and unreality" (59), su entrada en el mundo de los adultos y de la guerra tenía que llevarse a cabo, como no podía ser de otra manera, en una pelea y además en las turbias aguas del río Naguamsett “...ugly, saline, fringed with marsh, mud and seeweed... its movements were governed by unimaginable factors..." (68), asociado permanentemente al invierno y a una especie de letargo en que momentáneamente se sumen todos los estudiantes ante el inmediato futuro que les espera. El retorno a la normalidad escolar para el nuevo curso supone la aceptación sumisa de un mundo vulgar, grisáceo y rutinario, donde se enfatiza la necesidad de perpetuar una larga tradición académica que para Gene significa plegarse de nuevo a las reglas. Durante un tiempo vive abandonado a su suerte; tendrá que saber imponerse a las sutiles insinuaciones de otros muchachos de haber causado el accidente de Phineas, soportar humillaciones hasta entonces desconocidas para él y la sensación de sentirse perdido. Sin embargo, sabe adoptar una decisión trascendental para su integración en la sociedad: huir de la realidad es una alternativa que se presenta ya "...as meaningless, a lapse into nothing, an escape into nowhere" (173). El clima de guerra se impone definitivamente en la escuela: algunos profesores visten el uniforme militar y los sermones en la iglesia tienen resonancias marciales. El miedo y la ansiedad que causan la idea de la guerra empieza a ser inaplazable para los muchachos y la idea del alistamiento acapara cada vez más sus pensamientos.

Cuando Phineas regresa de nuevo a la escuela lo hace ya en el papel de perdedor en una carrera para la que no está preparado. Empieza a ser visto como el soñador que poco o casi nada nuevo tiene que ofrecer salvo su firme convicción de que la guerra no existe o a lo sumo es una falacia inventada por caducos líderes políticos empeñados en apartar a los jóvenes de su plena realización individual. Pero en su negativa Gene entiende que también hay un rechazo de todo impulso competitivo en el espíritu humano y la convicción firme de que la paz sólo es posible en un mundo en armonía, sin fisuras, donde la vida sea concebida como una extensión de su visión de los juegos y de los deportes en que “...there was no conflict except between athletes, something Greek-inspired and Olympian in which victory would go to whoever was the strongest in body and heart..." (144). Gene entonces empieza a ser consciente cada vez más de la diferencia entre su naturaleza y la de Phineas, y también de la diferencia entre el bien y el mal, entre un mundo de ilusiones y el mundo de la realidad. Acaba liberándose del miedo a no esconderse de la guerra y de las ambigüedades de la naturaleza humana cuando acepta la inevitabilidad del cambio y asume para sí la idea de que la guerra es "...like a test... and only the things and the people who've been evolving the right way survive" (117). Sobrevivir no es sino adaptarse a las circunstancias, plegarse a las necesidades que impone la realidad. Es además creer en un mundo con sus fracasos y sus logros, sus responsabilidades y compromisos. Acepta pues esa doble cualidad que existe en el espíritu humano y que él ha rechazado por su peculiar tendencia a sospechar de todo aquello que introduce lo imprevisible y espontáneo en su conducta. Reconoce ahora que ha logrado eliminar para siempre "...this vivid false identity; now I was acquiring, I felt, a sense of my own real authority, and worth; I had had many new experiences and I was growing up...” (148) porque ha encontrado un equilibrio entre idealismo y realidad, entre lo que el mundo debería de ser y lo que es en sí. 
Pero en todo proceso de cambio hay siempre implícita una idea de pérdida. Phineas, en efecto, es un personaje estático, que no aprende ni evoluciona ni llega a entender nunca el mundo que le rodea. Víctima de su propia inocencia, sólo le queda ya su desaparición (muere a consecuencia de una caída accidental en el edificio que pomposamente tiene la inscripción en latín "Here Boys Come to Be Made Men") ignorando para siempre la existencia del mal. Phineas no puede sobrevivir en un mundo que ignora la benevolencia de sus principios. Su idealismo pertenece a un pasado desaparecido o es al menos incompatible en un mundo dominado por el afán de poder y que concibe el lado lúdico del hombre como algo que hay que reprimir o simplemente transformar por otro juego más terrible, atroz y devastador, en la creencia de que "Games are all right in their place...but all exercise ... is aimed of course at the approaching Waterloo" (113).

La nueva manera de calibrar el mundo de Gene, por el contrario, le permite acceder a la sociedad y sus demandas: participa en la guerra, de la que dice nunca tuvo que matar a nadie, y logra su éxito personal plenamente y su armonía interior como hace saber en las páginas iniciales. A diferencia de otros, Gene aprendió en su momento que ante el verdadero enemigo de las relaciones humanas no cabe escapar ni construir líneas defensivas, ni tampoco acusar a las generaciones mayores, sino reconociendo que tanto su conflicto interior que le llevó a provocar la caída de Phineas como las guerras obedecen a una manifestación enfermiza de la conducta humana, son el resultado de los miedos y tensiones y la falta de comprensión, un mismo mal que distancia a los hombres y les convierte en seres insensibles, atenazados por el miedo, viviendo en el odio.

\section{OBRAS CITADAS}

Bıoom, H., ed. 2000. John Knowles's A Separate Peace. Philadelphia: Chelsea House Publishers.

Bryant, H.B. 1990. A Separate Peace: The War Within. Boston: Twayne Publishers.

Elly, A.A. 1999. “The Adult Image in Three Novels of Adolescent Life”. Ed. J. KARson. San Diego: Greenhaven Press. 33-35.

Foster, M.P. 1999. "Levels of Meaning in A Separate Peace". Readings on A Separate Peace. Ed. J. Karson. San Diego: Greenhaven Press. 89-96.

Karson, J., ed. 1999. Readings on A Separate Peace. San Diego: Greenhaven Press.

Knowles, J. 1964. Double Vision: American Thoughts Abroad. New York: Macmillan. . 1975. A Separate Peace. New York: Bantam Books.

_. 1985. “My Separate Peace.” Esquire March: 107-109.

Rosenfield, C. 1963. "The Shadow Within: The Conscious and Unconscious Use of the Double". Daedalus: A Journal of the American Academy of Arts and Sciences 92: 326-344.

Sarotte, G.N. 1978. Like a Brother, Like a Lover. Garden City: Doubleday.

Slethaug, G. E. 2000. “The Play of the Double in A Separate Peace." John Knowles's A Separate Peace. Ed. H. Bloom. Philadelphia: Chelsea House Publishers. 93-104. 